\title{
MANIFOLD EFFECTS OF THE CYANOGENIC LOCI IN WHITE CLOVER
}

\author{
RICHARD A. ENNOS \\ Department of Genetics, University of Liverpool*
}

Received 18.vi.80

\begin{abstract}
SUMMARY
In white clover alternate alleles $A c / a c$ and $L i / l i$ at two unlinked loci determine the presence/absence of cyanogenic glucosides and the enzyme linamarase respectively. Plants possessing both cyanogenic glucosides and enzyme are cyanogenic. Morphological measurements were made on a random sample of plants from a population polymorphic at both Ioci. Individuals possessing linamarase had larger leaves than those lacking the enzyme. Competition experiments between all phenotypes showed a significant effect of $L i$ phenotype frequency on total yield. Competitive interactions were such as to maintain polymorphism at the $L i$ locus. It is concluded that the pattern of variation at the $A C$ and $L i$ loci cannot be adequately explained by selection which discriminates between cyanogenic and acyanogenic phenotypes.
\end{abstract}

\section{INTRODUCTION}

In white clover (Trifolium repens $\mathrm{L}$.) the ability to release hydrogen cyanide $(\mathrm{HCN})$ from damaged leaves is under the control of two unlinked genes (Corkhill, 1943; Atwood and Sullivan, 1943). Locus Ac/ac determines the presence/absence of the cyanogenic glucosides linamarin and lotaustralin, locus $L i / l i$ the presence/absence of their hydrolysing enzyme linamarase. Presence is dominant to absence in both cases. Both substrate and enzyme must be present for the immediate release of $\mathrm{HCN}$. Thus individuals of phenotype $A c L i$ are cyanogenic, and phenotypes $A c l i, a c L i$ and acli are acyanogenic.

A number of workers have reported that cyanogenic individuals of $T$. repens are less heavily damaged by small herbivores than their acyanogenic counterparts (Crawford-Sidebotham, 1972; Angseesing, 1974; Dritschilo et al., 1979). If this were the only selective factor operating, natural populations of $T$. repens would become fixed for the cyanogenic phenotype. Surveys have shown, however, that over wide geographic areas $T$. repens populations are polymorphic at both the loci concerned with cyanogenesis (Daday, 1954). It is therefore pertinent to ask whether these loci have additional effects on the phenotype and fitness of individuals.

The first part of this report investigates whether variation at the $A c$ and $L i$ loci is associated with differences in morphology. This is followed by an analysis of the competitive fitness of clones which differ in phenotype at these two loci.

* Present address: Genetics Department, University of Newcastle, Newcastle-upon-Tyne, NE1 7RU. 


\section{MAterials AND METHODS}

100 seed heads were collected at least $5 \mathrm{~m}$ apart, from a long established permanent pasture near Chester (Grid SJ 384610) in which the frequency of cyanogenic phenotypes was:

$\begin{array}{lllll}\text { Phenotype } & A c L i & \text { Acli } & \text { acLi } & \text { acli } \\ \text { Frequency } & 0.12 & 0.48 & 0.10 & 0.30\end{array}$

500 plants g.own from this seed were scored for the presence/absence of cyanogenic glucosides and linamarase by the method of de Araujo (1976). 39 plants of each phenotype were then grown in the greenhouse in a fully randomized block for use in all subsequent experiments.

\section{(i) Morphological measurements}

The length and breadth of all leaflets, together with the petiole length were measured for the first expanded leaves on two randomly chosen stolons of each plant. The measurements of each parameter were averaged to give a single value for each plant.

\section{(ii) Root growth}

$5 \mathrm{~cm}$ cuttings from stolon tips were taken from 30 randomly chosen plants of each phenotype. Cuttings were rooted in $7 \mathrm{~cm}$ diameter polystyrene cups filled with calcium nitrate $(0.5 \mathrm{~g} /$ litre $)$ under constant illumination at $20^{\circ} \mathrm{C}$. The solution was changed every two days, and on day seven the length of the longest root produced was recorded. Four replicates were run, each being assigned to a separate fully randomized block.

\section{(iii) Competition}

$5 \mathrm{~cm}$ stolon tip cuttings were taken from 20 plants of each phenotype. Rooted cuttings of each phenotype were grown in pure stand and in every possible $1: 1$ combination at two densities; 4 and 8 plants $/ 20 \mathrm{~cm}$ pot. Cuttings were arranged in a circle within each pot, different phenotypes alternating around the pot in the $1: 1$ mixture. Each competitive treatment was replicated three times, each replicate being assigned to a separate randomized block.

Plants were grown outside, clipped to a height of $3 \mathrm{~cm}$ every two weeks to simulate the effects of non-selective grazing, and harvested after seven weeks (high density) and 11 weeks (low density). Above ground dry weight was recorded for each individual.

\section{RESULTS}

(i) Morphology

Analysis of variance was performed on the results with $A c / a c$ phenotype and $L i / l i$ phenotype as the two fixed effects (table $1 a, b, c)$. There is a significant effect of the Li locus on leaflet length and width $(P<0 \cdot 05$ in both cases), plants with linamarase tending to have longer and broader leaflets. 
TABLE 1

Analysis of variance of $(a)$ leaflet length, $(b)$ leaflet width, $(c)$ petiole length and $(d)$ root growth. Mean leaflet lengths $(a)$ and widths $(b)$ are given in $\mathrm{mm}$ below

\begin{tabular}{|c|c|c|}
\hline Source & d.f. & M.S.(a) \\
\hline$A c$ & 1 & 0 \\
\hline$L i$ & 1 & $565^{*}$ \\
\hline$A c \times L i$ & 1 & 24 \\
\hline $\begin{array}{l}\text { Between Plants } \\
\text { Within plants }\end{array}$ & 152 & 142 \\
\hline${ }^{*} P<0.05$ & $* * * P<0.001$ & \\
\hline Phenotype & mean (a) & mean $(b$ \\
\hline $\begin{array}{l}\mathrm{Li} \\
\mathrm{li}\end{array}$ & $\begin{array}{l}12.63 \\
11.96\end{array}$ & $\begin{array}{l}13.44 \\
12.74\end{array}$ \\
\hline
\end{tabular}

(ii) Root growth

Cuttings producing roots less than $10 \mathrm{~mm}$ long were entered as missing values in the analysis of variance (table $1 d$ ). There is highly significant "between plant" variation for root growth $(P<0 \cdot 001)$, but no significant effect of the $A c$ or $L i$ loci on this character.

\section{(iii) Competition}

The results are illustrated using replacement series diagrams (fig. 1) in which either the proportion of cyanogenic glucoside containing plants or the proportion of linamarase containing individuals is plotted against yield (de Wit, 1960). The total yields/pot, but not the yields of components, are independent variables (McGilchrist, 1965). Analysis of variance was performed on total yields/pot where the proportion of $A c$ phenotypes, the proportion of $L i$ phenotypes, and blocks were the three fixed effects (table 2 ). At high density there is a significant effect of the proportion of linamarase containing individuals on total yield $(\boldsymbol{P}=0.026)$. The yield of pure stands of linamarase-containing individuals is significantly lower than the yield of $1: 1$ mixtures of $L i$ and $l i$ phenotypes $(P<0.025)$.

\section{TABLE 2}

Analysis of variance of total yield of pots at (a) low density, $(b)$ high density, together with (c) mean yields of pots at high density ( $g$ dry wt.)

\begin{tabular}{lrll}
\multicolumn{1}{r}{ Source } & d.f. & M.S.(a) & M.S.(b) \\
$A c$ & 2 & 0.0699 & $2 \cdot 5154$ \\
$L i$ & 2 & 0.6608 & $6.3430^{*}$ \\
$A c \times L i$ & 4 & 0.4756 & 1.7105 \\
Blocks & 2 & 1.4847 & 0.2187 \\
Error & 16 & 0.5461 & 1.3628 \\
$* P=0.026$ & & & \\
(c) $L i$ pure stand & $1 L i: 1 l i$ & li pure stand \\
\multicolumn{2}{c}{$7 \cdot 2744$} & 8.9488 & 8.2044
\end{tabular}


a). Low density
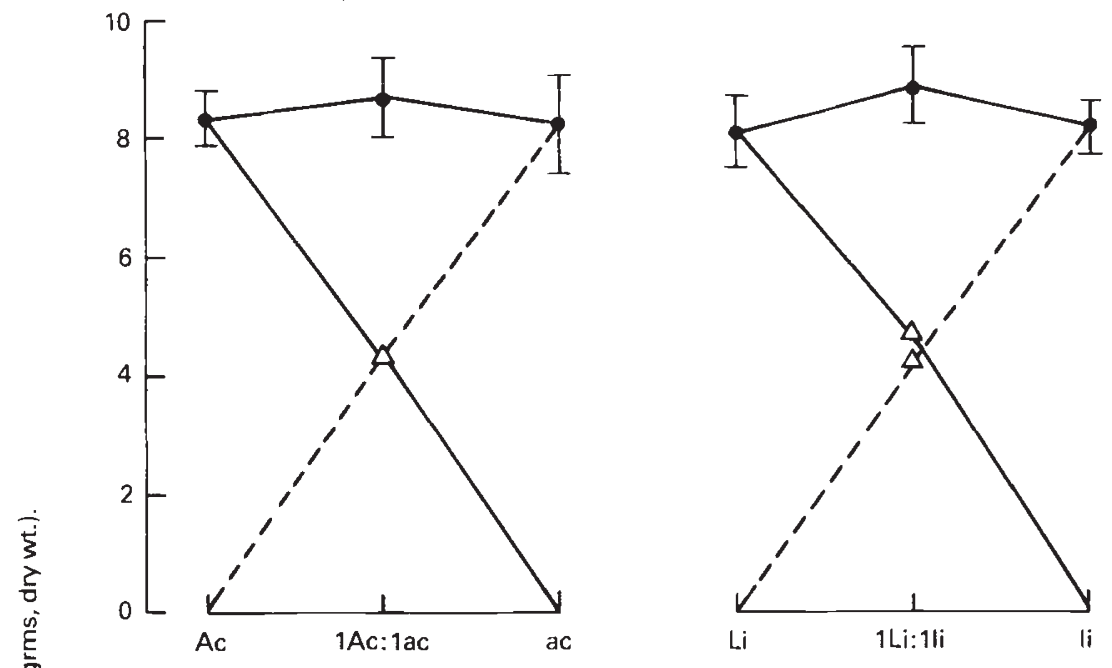

b). High density
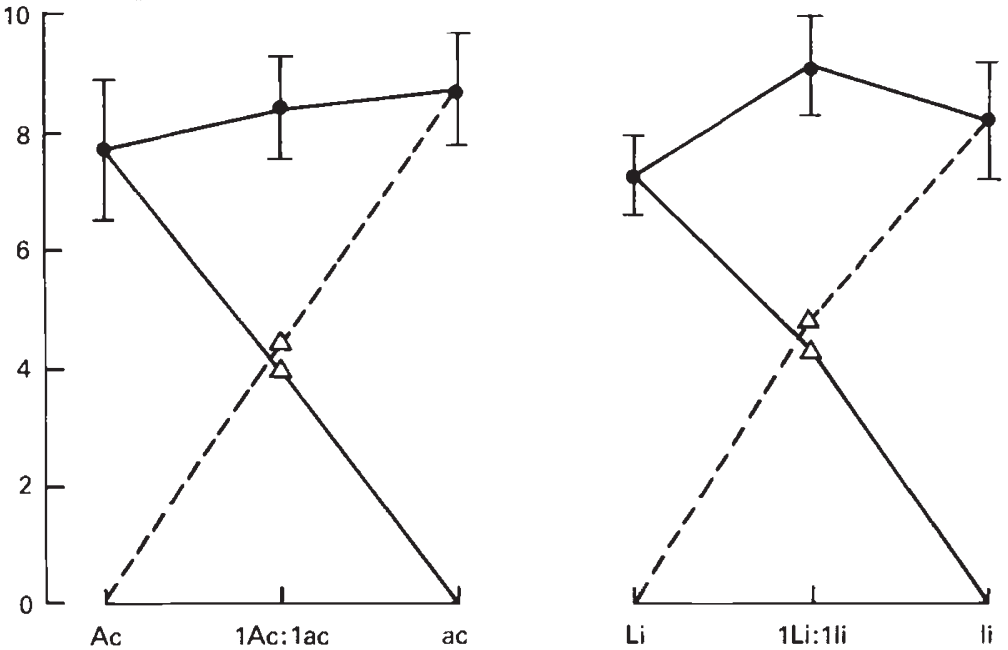

Composition of Mixture

FIG. 1.-Replacement series diagrams for dry weight per pot of phenotypes grown in pure stand and 1:1 mixtures at two densities. Means and 95 per cent confidence intervals are given.

\section{Discussion}

Two results emerge from this work. Within a single population, individuals of $T$. repens possessing the enzyme linamarase tend to have larger leaves than those without the enzyme. Therefore selection for leaf size will influence the frequency of $L i$ phenotypes in the population (Ennos, 1979). In addition there is a significant effect of the $L i$ locus on the competitive 
ability of clones. It is possible that the differences in leaf size may underlie the observed differences in competitive ability.

Seedling recruitment of $T$. repens in permanent pastures occurs at a very low rate (Turkington et al., 1979, personal observation). Populations consist of many long lived clones competing over considerable periods of time. Under these circumstances the vegetative competitive ability of the individual will, to a large extent, determine its fitness. It is interesting therefore to use estimates of competitive fitness derived experimentally (table 3 ) to determine whether a stable mixture of $L i$ and $l i$ phenotypes can be maintained as a result of competitive interactions between clones.

TABLE 3

Yields and fitness estimates of $\mathrm{Li}$ and li phenotypes obtained from high density competition experiment

$\begin{array}{lcc} & \text { Yield (g dry wt.) } & \text { Fitness } \\ L i \text { in competition with } L i & 3.64 & 0.75 \\ L i \text { in competition with } l i & 4.29 & 0.89 \\ l i \text { in competition with } L i & 4.83 & 1.00 \\ l i \text { in competition with } l i & 4.10 & 0.85\end{array}$

The model of Cockerham and Burrows (1971) for populations of interacting autogenous components is appropriate. This assumes that competition is limited to pairwise interactions between components, with random distribution of these components in the population. For a two-component mixture there is a stable equilibrium when $t_{12}>0$ and $t_{21}>0$ where $t_{12}=$ fitness component 1 in competition with component 2-pure stand fitness component $2, t_{21}=$ fitness component 2 in competition with component 1 -pure stand fitness component 1 . The equilibrium frequency of component 1 is then given by $\hat{p}_{1}=t_{12} / t_{12}+t_{21}$.

The fitnesses of $L i$ and $l i$ phenotypes at high density satisfy the conditions for stable polymorphism, and predict an equilibrium frequency of 0.13 for the $L i$ phenotype. This compares with an observed frequency of 0.22 in the permanent pasture from which the material was derived. These results suggest that competitive interactions may be important in maintaining polymorphism at the $L i$ locus in natural populations, especially where the density of $T$. repens is high, and intraspecific competition is intense. Schultz et al. (1968), Allard and Adams (1969), Putwain and Harper (1972), Khan et al. (1975) and Antonovics (1978) have all discussed the potential importance of intergenotypic competition in maintaining polymorphism in plant populations, but the subject has received little experimental attention.

Many other studies of the cyanogenic polymorphism in $T$. repens have concentrated on selective factors discriminating between cyanogenic and acyanogenic phenotypes (Bishop and Korn, 1969, Angseesing, 1974, Foulds and Young, 1977, Dritschilo et al., 1979). The results reported here suggest that besides determining the presence/absence of linamarase the $L i$ locus (or loci in tight linkage disequilibrium) has other selectively important effects on the plant not associated with cyanogenesis, which may influence both phenotype frequency and maintenance of polymorphism at the $L i$ locus. These additional effects must be taken into account if we are to provide an adequate explanation for the observed pattern of gene frequency, and the maintenance of polymorphism, at the $A c$ and $L i$ loci. 
Acknowledgments-I would like to thank Professor A. D. Bradshaw and Dr J. A. Bishop for their advice and encouragement, and the University of Liverpool for a Research Studentship which enabled me to carry out this work.

\section{REFERENCES}

AllARD, R. W., AND ADAMS, J. 1969. Population studies in predominantly self-pollinating species. XIII. Intergenotypic competition and population structure in barley and wheat. Am. Nat., 103, 621-645.

ANGSEESING, J. P. A. 1974. Selective eating of the acyanogenic form of Trifolium repens. Heredity, 32, 73-83.

ANTONOVICS, J. 1978. The population genetics of mixtures. In Plant Relations in Pasture, ed. J. Wilson. C.S.I.R.O. Melbourne.

ARAUJO, A.M. DE. 1976. The relationship between altitude and cyanogenesis in white clover (Trifolium repens L.). Heredity, 37, 291-293.

ATWOOD, S. S., AND SULLIVAN, J. T. 1943. Inheritance of a cyanogenetic glucoside and its hydrolysing enzyme in Trifolium repens. J. Heredity, 34, 311-320.

BISHOP, J. A., AND KORN, M. E. 1969. Natural selection and cyanogensis in white clover Trifolium repens. Heredity, 24, 423-430.

COCKERHAM, C. C. AND BURROWS, P. M. 1971. Populations of interacting autogenous components. Amer. Nat., 105, 13-29.

CORKHILL, L. 1943. Cyanogenesis in white clover (Trifolium repens L.). V. The inheritance of cyanogenesis. N. Z. Jl. Sci. Technol., 23B, 178-193.

CRAWFORD-SIDEBOTHAM, T. J. 1972. The role of slugs and snails in the maintenance of the cyanogenesis polymorphisms in Lotus corniculatus and Trifolium repens. Heredity, 28, 405-411.

DADAY, H. 1954. Gene frequencies in wild populations of Trifolium repens. 1. Distribution by latitude. Heredity, 8, 61-78.

DRITSCHILO, W., KRUMMEL, J., NAFUS, D., AND PIMENTEL, D. 1979. Herbivorous insects colonizing cyanogenic and acyanogenic Trifolium repens. Heredity, 42, 49-56.

ENNOS, R. A. 1979. Natural selection in Trifolium repens populations polymorphic for cyanogenesis. Ph.D Thesis, University of Liverpool.

FOULDS, W., AND YOUNG, L. 1977. The effect of frosting, moisture stress and potassium cyanide on the metabolism of cyanogenic and acyanogenic phenotypes of Lotus corniculatus and Trifolium repens. Heredity, 38, 19-24.

KHAN, M. A., PUTWAIN, P. D., AND BRADSHAW, A. D. 1975. Population inter-relationships 11. Frequency dependent fitness in Linum. Heredity, 34, 145-163.

McGILCHRIST. C. A. 1965. Analysis of competition experiments. Biometrics, 21, 975-985.

PUTWAIN, P. D., AND HARPER, J. L. 1972. Studies in the dyanamics of plant populations. V. Mechanisms governing the sex ratio in Rumex acetosa and $R$. acetosella. J. Ecol., 60 , 113-129.

SCHULTZ, W. M., BRIM, C. A., AND USANIS, S. A. 1968. Intergenotypic competition in plant populations. 1. Feedback systems with stable equilibria in populations of autogamous homozygous lines. Crop Sci. 8, 61-66.

TURKINGTON, R., CAHN, M. A., VARDY, A., AND HARPER, J. L. 1979. The growth, distribution and neighbourhood relationships of Trifolium repens in a permanent pasture. III. The establishment and growth of Trifolium repens in natural and perturbed sites. $J$. Ecol., 67, 231-243.

WIT, C. T. DE. 1960. On competition. Versl. landbouwk. Onderz. Rijkslandbproestfn, 66, 1-82. 